\title{
Renal Metastases in the Thyroid Gland: Is it a new Trend?
}

\author{
Marica Grasso*1, Luciana Costigliola ${ }^{2}$, Francesca Ciorra ${ }^{2}$, Antonello Niglio ${ }^{2}$ and Claudia Andretta ${ }^{2}$ \\ ${ }^{1}$ Faculty of Medicine and Surgery, University of Salerno, Italy \\ ${ }^{2}$ UOC General Surgery, AORN “A. Cardarelli”. Naples, Italy
}

Received: May 26, 2018; Published: June 06, 2018

*Corresponding author: Marica Grasso,Doctorate student, University of Salerno, Faculty of Medicine, Surgery and Dentistry, Via S. Allende, 84080 Baronissi, Salerno, Italy

Abstract

Intra-thyroid metastases are a rare occurrence. Previous research characterized melanoma and breast carcinoma as the commonest primary lesions leading to thyroid metastases, but more recent studies demonstrate that renal cell carcinoma (RCC) is now the most prevalent. The aims of this study is to report our experience and to analyze the clinical characteristics of patients with thyroid involvement of RCC

Keywords: Thyroid; Metastases; Renal Cell Carcinoma; Cancer

\section{Introduction}

Intra-thyroid metastases are a rare occurrence, and represents only $1-3 \%$ of all thyroid cancers[1]. It is still uncertain which factors might come into play and inhibit the development of further tumors in thyroid gland originating from a distant primary tumour. Hadfield introduced the concept of «the dormant cancer cell» and believed that inhibition of mitosis could be a consequence of anoxia[2]. Another hypothesis is that local hormonal factors and a high tissue iodine concentration may potentially affect metastatic cell growth in the thyroid gland [3]. The third hypothesis is that the thyroid gland has very rich vascularization, and it has been suggested that disruption of the blood flow by goiter or thyroiditis predisposes for deposition of metastatic cells [4]. The development of metastasis probably involves a complex interplay between genetic informations carried by the tumour cells, the microenvironment of different tissue types, and genetic onset of the patient [5].

Previous researches characterized melanoma and breast carcinoma as the common primary lesions leading to thyroid metastases [6], but more recent studies demonstrate that renal cell carcinoma (RCC) is the most prevalent matastases that arise into the thyroid gland nowadays. From 1964 to 2006, the literature depicts RCC metastases to the thyroid gland as a rare occurrence, with only 113 documented cases. However, this disease phenomenon is emerging with increasing frequency in recent literature and warrants awareness amongst clinicians when investigating thyroid nodules[7-10].
Autopsy studies of patients with known metastatic malignancy have suggested that thyroid metastases are under-diagnosed and may occur in up to $20 \%$ of patients[11]. The aims of this study is to analyze the clinical characteristics of patients with thyroid involvement of RCC. A common theme amongst these cases is a long lag phase between the treatment of RCC and the development of thyroid metastases.

\section{Case Report}

A 68-year-old male patient who had been subjected to left nephrectomy for renal cancer in 2008, was admitted in January 2018 into our Institution to undergo intervention for multinodular goiter in euthyroidism. Ultra Sound examintion, performed in October 2007, showed a mass in the right thyroid lobe, measuring $4.2 \mathrm{x}$ $4.7 \mathrm{~cm}$, Scintigraphy was performed in April 2008 and showed hypocaptation. Two Fine Needle Agobiopsy (FNAB) were performed respectively in 2008 and 2011 and both were negative (Tyr 2). In February 2018 he was subjected to total thyroidectomy, has no post-operative complications and was then discharged on second day.

\section{Results}

Histological examination shows thyroid metastasis from renal cell carcinoma (RCC). Immunohistochemistry shows: TTF1-, thyroglobulin-, CD10 +/-, CK8/18 +/-and CKAE1/AE3-/+ thus confirming the renal origin of the neoplasia. 


\section{Discussion}

Renal cell carcinoma (RCC) is emerging as one of the most common malignancy to metastasize to the thyroid gland. Metastatic RCC should be then included in the differential diagnosis of a new thyroid mass. Treatment directed at the thyroid metastasis results in prolonged survival and definitive resolution of some symptoms. The thyroid gland is highly vascularised and on this basis one would expect it would be a common site for metastases. Paradoxically, however, metastases only occurs in a small percentage of all thyroid nodules. Protective factors against metastatic deposits in the thyroid gland are thought to be its high concentration of iodine, and the filtering capability of pulmonary capillaries. In the past decades, autopsy studies have suggested that the commonest primary sources of thyroid metastases were melanoma (39\%) and breast carcinoma (21\%).

However, a more recent review of clinical cases suggests that renal cell carcinoma predominates as the leading cause of metastases from non-thyroid malignancies to the thyroid gland (48.1\%). According to literature, RCC displays a pattern of late metastatic spread to the thyroid gland, with a median time interval of 6-12.5 years and a mean interval time of 9 years. It occurs with high frequency in elderly patient, between 60 and 80 years of age, with a slight excess of females The treatment for metastatic disease in the thyroid gland from kidney cancer consists of surgery, either partial resection or total thyroidectomy, as it was performed in our case. To achieve a permanent resolution of symptoms or a survival improvement, active surgical intervention is particularly relevant if there are no other signs that the tumour has spread, however palliative interventions to relieve specific symptoms as stridor or compression, may also be appropriate.
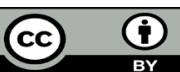

This work is licensed under Creative Commons Attribution 4.0 License

Submission Link: https://biomedres.us/submit-manuscript.php

\section{References}

1. Chen H, Nicol TL, Udelsman R (1999) Clinically significant, isolated metastatic disease to the thyroid gland. World J Surg 23(2):170-180.

2. Hadfield G (1954) The Dormant cancer cell. BMJ 2:607-610.

3. Mattavelli F, Collini P, Pizzi N, Carlo Gervasoni,Elisabetta Pennacchioli, et al.(2008) Thyroid as a target of metastases. A case of foregut neuroendocrine carcinoma with multiple abdominal metastases and a thyroid localization after 21 years. Tumori 94:110-113.

4. Marotta V, Sciammarella C, Chiofalo M, Gambardella C, Bellevicine C, et al. (2017) Hashimoto's thyroiditis predicts outcome in intrathyroidal papillary thyroid cancer. Endocrine-Related Cancer 24(9): 485-493.

5. Wikman H, Vessella R, Pantel K (2008) Cancer micrometastasis and tumor dormancy. APMIS 116(7-8):754-770.

6. Chung AY, Tran TB, Brumund KT, Weisman RA, Bouvet M (2012) Metastases to the thyroid: a review of the literature from the last decade. Thyroid22(3): 258-268.

7. Cichon S, Anielski R, Konturek A, Barczynski M, Cichon W (2006) Metastases to the thyroid gland: seventeen cases operated on in a single clinical center. Langenbecks Arch Surg 391(6):581-587.

8. Iesalnieks I, Trupka A, Raab M, Glockzin G, Woenckhaus M, et al. (2007) Renal cell carcinoma metastases to the thyroid gland-8 cases reported. Thyroid 17(1):49-52.

9. Iesalnieks I, Winter H, Bareck E, Sotiropoulos GC, Goretzki PE, et al. (2008) Thyroid metastases of renal cell carcinoma: clinical course in 45 patients undergoing surgery. Assessment of factors affecting patients' survival. Thyroid 18(6):615-624.

10. Valle LA, Kloos RT (2011) The prevalence of occult medullary thyroid carcinoma at autopsy. J Clin Endocrinol Metab 96(1):109-113.

11. Conzo G, Avenia N, Ansaldo G, Calò P, De Palma M, et al. (2017) Surgical treatment of thyroid follicular neoplasms: results of a retrospective analysis of a large clinical series. Endocrine 55(2):530-538. 